THE COMPETITIVE EFFECTS OF TRANSMISSION CAPACITY IN A DEREGULATED ELECTRICITY INDUSTRY

\author{
Severin Borenstein \\ James Bushnell \\ Steven Stoft
}

Working Paper 6293 
NBER WORKING PAPER SERIES

\title{
THE COMPETITIVE EFFECTS OF TRANSMISSION CAPACITY IN A DEREGULATED ELECTRICITY INDUSTRY
}

\author{
Severin Borenstein \\ James Bushnell \\ Steven Stoft
}

Working Paper 6293

http://www.nber.org/papers/w6293

\section{NATIONAL BUREAU OF ECONOMIC RESEARCH 1050 Massachusetts Avenue \\ Cambridge, MA 02138 \\ November 1997}

The authors would like to thank Carl Blumstein, Glenn Ellison, Joe Farrell, Paul Joskow, Ed Kahn, Bart McGuire, Shmuel Oren, Scott Stern, Matt White, participants in the April 1996 StanfordBerkeley IOfest, and seminar participants at U.C. Berkeley and MIT for helpful comments and discussions. This research was partially funded by the California Energy Commission under contract \#700-93-003, amendment 2. Any opinions expressed are those of the authors and not those of the National Bureau of Economic Research.

(C) 1997 by Severin Borenstein, James Bushnell and Steven Stoft. All rights reserved. Short sections of text, not to exceed two paragraphs, may be quoted without explicit permission provided that full credit, including $(C$ notice, is given to the source. 
The Competitive Effects of Transmission Capacity

in a Deregulated Electricity Industry

Severin Borenstein, James Bushnell

and Steven Stoft

NBER Working Paper No. 6293

November 1997

\begin{abstract}
In an unregulated electricity generation market, the degree to which generators in different locations compete with one another depends on the capacity to transmit electricity between the locations. We study the impact of transmission capacity on competition among generators. We show that there may be no relationship between the effect of a transmission line in spurring competition and the actual electricity that flows on the line. We then investigate the equilibria that are likely to result as transmission lines between previously unconnected locations are built and expanded. We demonstrate that limited transmission capacity can give a firm the incentive to restrict its output in order to congest transmission into its area of dominance. This analysis is applied to a model of California's forthcoming deregulated electricity market. Our results indicate that at least one firm could have an incentive to strategically induce transmission congestion and that relatively small investments in transmission may yield surprisingly large payoffs in terms of increased competition.
\end{abstract}

Severin Borenstein

Haas School of Business

University of California

Berkeley, CA 94720-1900

and NBER

borenste@haas.berkeley.edu
James Bushnell

UC Energy Institute

2539 Channing Way

Berkeley, CA 94720-5180
Steven Stoft

UC Energy Institute

2539 Channing Way

Berkeley, CA 94720-5180 


\section{Introduction}

Electricity transmission facilities have long been recognized as central elements in the efficient planning and operation of electricity systems. Traditionally the role of large, inter-utility transmission paths has been to exploit regional generation cost differences through the use of short and long term transactions between vertically integrated, regulated utilities. Increased transmission capacity between service areas also allowed utilities to take advantage of the economies such links provide for meeting reserve margins as well as seasonal load variations between regions such as the Pacific northwest and the southwest.

The value of transmission facilities in this context was driven by the concept of "used and useful." Before making an investment in transmission facilities, an investor-owned utility would have to demonstrate the "public convenience and necessity" of the new line. The dominant measure of the necessity of a line was the level of congestion along the path served by that line. In other words, if a line was not used, it was not very useful. Since, in theory, significant cost differences between regions would lead to maximum loading of a line, the concept of used and useful was appropriate for the traditional setting.

In the U.S., and many other countries around the world where the electricity generation industry is being deregulation, transmission facilities will provide important competitive links between potentially isolated markets. Transmission facilities allow for a degree of competitive entry into these markets that would not otherwise exist. Therefore, in addition to providing the ability to exploit the cost advantages of large inter-connected systems, transmission facilities will play a central role in mitigating the potential for market power abuses.

Of course, transmission lines will also continue to be important for taking advantage of regional cost differences. If one market has a very large cost advantage over another, the transmission paths connecting those markets will most likely be 
congested with flows from the low-cost market to the high-cost one. Thus, when there are large differences between markets, the competitive effect of transmission lines is relatively straightforward: power will flow into higher-priced markets up to the capacities of the links. If there is a monopoly supplier in the high-price market, it will view these imports as a competitive fringe with a capacity constraint and will respond accordingly.

It is important to recognize that the way the firms themselves view transmission capacity will dramatically change as the industry becomes less regulated. A regulated firm would have little or no interest in inducing congestion into its market. A profit maximizing firm, however, may find it quite profitable to do just that, thereby becoming a monopolist on any residual demand left unserved by imports from other regions. Any forecasts or predictions of market outcomes in a deregulated environment must take these changing incentives into account. This is especially critical in the context of determining the geographic scope of markets for the purposes of analyzing the potential for market power.

We examine the competition-enhancing role of transmission facilities in the context of a model of two geographically distinct electricity markets. This model, for example, can be thought of as a first-level approximation to the market distinctions between northern and southern California. In the situation where each market is dominated by a single supplier, the benefits of increased transmission capacity manifest as greater competition, in some cases with less actual power flow. The mere threat of competitive entry that is provided by additional transmission capacity acts as a restraining influence on the dominant supplier in each market, causing each to produce nearer to competitive levels even though the threatened imports are not in fact realized. Thus, the notion of "used and useful" could lead to poor policy decisions in this context, since unused capacity on a transmission path may still be providing important benefits by discouraging anticompetitive behavior. 
In section 2 , we describe the issues and choices faced by firms in separate markets that have the potential to be geographically distinct. In section 3 , we introduce a model of two identical, but geographically distinct, markets that are linked through a single transmission path. We show that the capacity of this transmission path plays a crucial role in determining the market outcomes and derive an expression for the "threshold" transmission capacity that is sufficient for completely integrating these two markets. We show that for transmission capacities less than this threshold capacity, no pure-strategy Cournot equilibrium outcome can exist. Section 4 presents an analysis of the potential mixed-strategy outcomes for transmission capacities below the threshold levels. Section 5 discusses several insights and generalizations of these results. In Section 6, we extend the analysis to asymmetric markets. In Section 7 , these extensions are applied to a model of California's forthcoming deregulated electricity market. In this section, we demonstrate the potentially very significant impact on this market of the capacity of the major north-south transmission path. Our conclusions are summarized in section 8 .

\section{Geographic Market Distinctions}

At first glance, electricity markets resemble any other in which there are spatially separated markets between which trade is possible. Consider two markets, which we call North $(N)$ and South $(S)$, that are identical in every respect. Each has a monopoly supplier with identical costs, firms $n$ and $s$, respectively. If these two regions were completely separate, there would be identical monopolistic solutions in the two regions. If, on the other hand, each producer were able costlessly to ship very large quantities into the other's market, the markets could no longer be considered geographically distinct. There would instead be a single market served by a duopoly. 
When one considers the unusual physical properties of "transporting" electricity, this standard trade problem exhibits some surprising characteristics. First, electricity can be rerouted or reshipped almost costlessly. A marketer can buy electricity and, if lines are not congested, have it delivered to (or consumed at) a different location at virtually no cost. This means that price differences can be easily arbitraged. Second, electricity is perfectly standardized so the market deals in a completely homogeneous good. As a result, if $n$ tries to ship $10 \mathrm{MW}$ to market $S$ and $s$ decides to ship $9 \mathrm{MW}$ to $n$, only $1 \mathrm{MW}$ of power actually flows over the line. In contrast, a Ford that is exported to Japan is actually shipped, not netted out from the number of Toyota's exported to the U.S. Lastly, most studies of geographic trade barriers, which consider shipping, highway, or rail transportation, do not assume constraints on shipping capacity. It is simply not a binding constraint for most spatially distinct markets. ${ }^{1}$

Homogeneity of the product, costless shipping, and symmetric markets lead to a somewhat surprising result: the transmission line causes prices to decline and outputs to increase, but no power actually flows on the connecting line. This means that although the line is not used, it is still very useful, because is keeps prices low. Even if the two markets were not perfectly symmetric, there may be very little flow on the line relative to the additional output that would be sold in each market. The threat of competition is all that is really needed, and the line (if it is big enough) provides that threat. Thus, if a connecting line is of sufficient capacity to reduce market power as much as possible, it may appear to be over built and under used.

This raises the question of how big a line is needed to induce duopolistic, instead of monopolistic, behavior? Clearly, the answer need not be related to the actual power flow on the line.

\footnotetext{
${ }^{1}$ Natural gas markets in some areas may also fit this description. These results would also apply to these markets, to the extent that there are firms with market power.
} 
More generally, we would like to know the effect of any given size line on the degree of competition between the firms at each end of the line.

\section{The Competitive Effect of a Trans- mission Line}

If we assume these same two markets are connected by an extremely low-capacity (thin) line, then each supplier would almost ignore the other, because each would know that the other could affect it very little. Thus, we would have something close to the two-monopoly solution in spite of the connecting line. The actual outcome, however, is more complicated than this, because it is not optimizing behavior for either firm to leave the line unused. ${ }^{2}$

We assume, for now, that firms follow Cournot strategies and are therefore quantity setters. We assume quantity setting due to the severe constraints that the need to commit generation capacity in advance puts on production. ${ }^{3}$ In section 5 , we discuss

\footnotetext{
${ }^{2}$ Throughout the analysis in this paper, we ignore two further complexities of electricity transmission: loop flow and reactive power. These are no doubt important factors, but including them in the analysis would greatly complicate the model without changing our basic points. It is unlikely that the strategic importance of transmission capacity would decrease if these other factors were explicitly considered.

${ }^{3}$ Wolak, 1996, provides evidence that electricity generators in the U.K. have used plant availability to compete in quantities in the short run. Klemperer and Meycr, 1989, present a model of supply curve competition, which Green and Newbery, 1992, apply to the UK market. Wolfram's, 1996, analysis finds that U.K. prices are below those that the Cournot model would predict, but argues that the explanation might be the threat of regulation. von der Fehr and Harbord, 1993, suggest a multi-unit auction approach to evaluating competition in electricity generation markets. While these approaches are more complex than the Cournot analysis, we see no reason that the hasic effects we identify here wouldn't also obtain in other
} 
the Cournot assumption at greater length and consider how the analysis changes if firms are assumed to compete in prices.

Assume that the two firms, $n$ and $s$, have identical cost functions that exhibit non-decreasing marginal cost, and that demand in each market, $N$ and $S$, is the same, $P(Q){ }^{4}$ With no connecting line, each firm will produce the single-market monopoly quantity, $Q_{m}$, and charge the monopoly price, $P_{m}$. With a sufficiently large line, the prices in the two markets will be equal to one another and will equal the unconstrained Cournot duopoly equilibrium price for the combined market with two identical firms, which we will call $P_{c}{ }^{5}$

To complete the characterization of the markets, we must also describe how transmission is allocated and priced. We assume that the transmission grid is operated by an entity that attempts to maximize social welfare by providing price signals to induce efficient use of the grid. The result is known as "nodal pricing." 6 Under this assumption, if there is no congestion, energy prices are the same everywhere in the network. When there is congestion in the network, transmission capacity is rationed with price. The effective "cost" of transmission is simply the nodal price difference between the node in which the power is injected into the network and the node where it is consumed. Thus, the grid operator collects the congestion rents associated with a transmission line, but never deters line use with a positive price when the line is uncongested. Even if the two producers wished to charge different prices in the two markets, the grid operator would arbitrage the price differences as long as it was feasible to ship power between the two markets.

oligopolistic models.

${ }^{4}$ We will also assume that the profit functions of firms in a single market, or in a fully merged market without transmission constraints, are strictly concave in their own output.

${ }^{5}$ For now, and throughout most of this analysis, we assume that there are no line losses - energy can be transported costlessly. We discuss line losses in section 5 .

${ }^{6}$ See Bohn et. al., 1984, for a description and analysis of nodal pricing. 
Variations of nodal pricing have been adopted or proposed in several electricity markets throughout the world. Although we adopt the conventions of nodal pricing in order to illustrate our results in the context of a familiar paradigm, our results do not depend upon this method of transmission pricing. ${ }^{7}$ We require only that transmission capacity be allocated efficiently, which implies that the cost of transmission is equal to the difference between locations in the price of power. ${ }^{8}$

Beginning from the two-monopoly equilibrium with no connecting line, if a very thin line were then built, either firm could improve its profits by increasing output. If firm $n$ continues to produce its monopoly quantity and firm $s$ increases its output slightly, half of that increase will go to each market. The demand curve seen by firm $s$ for this range of output is the sum of the two market demand curves minus the output of firm $n$. This will be true until $s$ has increased its output by $2 k$ units and $k$ units are being shipped to market $N$, just barely congesting the line. When firm $s$ increases its production beyond $2 k$ greater than firm $n$, the line becomes congested. Further increase by $s$ will cause $P^{S}$ to drop below $P^{N}$, and $s$ will receive $P^{S}$ for all of its output. For output levels in this range, firm $s$ faces a demand curve equal to its local demand curve shifted to the right by $k$, the capacity of the line.

To see that it would always be profitable for one firm to expand its output in the presence of a very thin line (if the other firm did not), note that if neither firm changed its output then the line would be uncongested. If the line is uncongested, then each firm faces (locally) the same problem it would face if there were no transmission constraint, the duopoly market conditions. In that case either firm would want to expand it output to its Cournot duopoly best response. Of course, with a

\footnotetext{
${ }^{7}$ An earlier version of this paper (Borenstein, et al., 1996) treated transmission capacity as a costless, congestible public good.

${ }^{8}$ Chao \& Peck (1996) have proposed an alternative system of transmission pricing that also meets these conditions.
} 
very thin line, a firm would be able to increase its output only slightly before it would congest the line.

More generally, one can derive the best-response (in quantity) functions of each firm in the presence of a line of size $k$. Figure 1 shows the best response function of firm $s$ when $k$ is small. When $n$ is producing nothing, the best response of $s$ is to produce its optimal quantity given that the line will be congested from $S$ to $N$. Under a nodal pricing regime, this quantity will be the monopoly output for the firm when it is faced with its native demand in the south shifted to the right by $k .{ }^{9}$ We denote this quantity as $Q_{m}^{+}$. When $n$ is producing up to $Q_{m}^{+}-2 k$, the best response of $s$ is to produce $Q_{m}^{+}$. As $n^{\prime}$ 's output rises above $Q_{m}^{+}-2 k$, the best response of $s$, at least locally, will be to produce $2 k$ units more than $n$. To see that this is the best strategy for firm $s$, assume the contrary, that $s$ produces $Q_{s}<Q_{n}+2 k$, where $Q_{n}$ is the quantity produced by firm $n$. Note that if $s$ produces such a $Q_{s}$, the line will be uncongested and the prices in the two markets will be equal. ${ }^{10}$ This is then effectively a single Cournot duopoly market. In such a market, if the line was uncongested and $s$ was producing below the level of its unconstrained best quantity response (the thick line in figure 1), it would want to increase output. We assume, for now, that due to the small size of the transmission line, both firms are well below their unconstrained best responses. Thus, this contradicts the assumption that $s$ would want to produce less than $Q_{n}+2 k$.

As n's output continues to rise, however, at some point it becomes more profitable for $s$ to switch to a much less aggressive strategy: $s$ will then allow $n$, to export $k$ units to market $S$

\footnotetext{
${ }^{9}$ Under nodal pricing, firm $s$ would receive the southern price for all its units of production, including the $k$ units that flow to the northern market.

${ }^{10}$ To see that $Q_{n}+2 k$ is necessary in order to congest the line, recall that the prices in the market must be equal if the line is uncongested. Starting from $Q_{s}=Q_{n}$, this means that any increase in production by $s$ will be distributed evenly between the $S$ and the $N$ market, with half of any additional ontput being shipped to $N$. Thus, in order to congest the line, $s$ must produce $2 k$ more than $n$.
} 
and will maximize its own profits given the residual demand it faces $P(Q+k)$, which is $s$ 's native demand shifted leftward by $k$. Firm $s$ is then effectively a monopolist on this residual demand curve. We call this the "passive strategy." We define $Q_{m}^{-}$to be the optimal passive strategy output, and note that $Q_{m}-k<Q_{m}^{-}$; in the passive strategy, the passive firm does not "fully accommodate" imports. ${ }^{11}$

Thus, each firm's best-response function slopes upward over some range and then discontinuously jumps to a smaller quantity if the other firm's output is sufficiently great. At the smaller quantity, the line will be congested carrying power into its region. With these best-response functions, we can show that the functions will not cross if $k$ is sufficiently small. That is, there will be no pure-strategy equilibrium.

Result 1 For transmission lines that have sufficiently small capacity, there is no pure strategy equilibrium for the symmetric Cournot duopoly.

We prove this as a subcase of a later result, but the intuition is straightforward: If firm $s$ is sufficiently aggressive in expanding output in order to be a net exporter of $k$ to the other market, then the firm $n$ 's best response will be to play the passive strategy, $Q_{m}^{-}$. But, $s$ would respond to the passive strategy by producing just $2 k$ more than the passive quantity. If $k$ is sufficiently small, $n$ 's best response to $Q_{m}^{-}+2 k$ is to produce

\footnotetext{
${ }^{11} Q_{m}^{-}>Q_{m}-k$ is the condition that imports of $k$ into the market would not cause the incumbent firm to restrict output so much as to drive up price. To see that this must be the case, consider the incumbent's position if it were to respond to imports of $k$ by reducing its own output by $k$ from its previous (zero import) optimizing quantity. In that case, the market price would be the same as before the imports and the effect on price of selling one more unit would be the same as before, but the incumbent would be selling fewer units. Thus, it's marginal revenue would be greater than before. So long as MC in non-decreasing, this implies that the incumbent would want to increase quantity.
} 
$Q_{m}^{-}+4 k$ and ship $k$ back to the $s^{\prime}$ s market. As this escalates, eventually one firm again finds that it would prefer playing the passive strategy to further escalation.

When there is no pure strategy equilibrium, there will still be a mixed-strategy equilibrium. This will be the case for small enough $k$. We explore the exact nature of the mixed strategy in the following section.

As $k$ increases the problem changes somewhat. While for some $k$ a firm might find it worthwhile to congest the line to the other market by producing $2 k$ more than the other firm, there will never be a best response that involves producing more than the unconstrained Cournot duopoly best response. Figure 2 shows the situation that obtains if $k$ is large enough that the unconstrained Cournot duopoly best response is feasible for some outputs of the other firm. Rather than sloping upward until the point at which the firms switches to the passive strategy of allowing imports, the best response function slopes upward until it hits the unconstrained Cournot duopoly best-response function, and then it slopes backward, coinciding with the unconstrained Cournot duopoly best-response function, until the discontinuity point. There is still a discontinuity point at which the firm's best response to increasing output of the opponent is to revert to the passive strategy of maximizing profits on the residual demand curve when the other firm exports $k$ into its market.

That point of discontinuity, however, occurs at a larger output of the opposing firm as $k$ increases. Let $Q_{s w}$ be the opponent's quantity at which it is optimal for a producer to switch from the aggressive strategy of producing $2 k$ more than the opponent to the passive strategy of allowing the opponent to transmit $k$ into its market.

Result 2 The quantity of the opposing firm at which the best response switches from aggressive to passive, $Q_{s w}$, is increasing in line capacity, $k$. 
The reason for this is that while an increase in $k$ (weakly) increases the payoff to the aggressive strategy, it strictly decreases the payoff from the passive strategy (so long as the passive strategy still involves producing positive quantity). Thus, it takes a more aggressive choice by the opposing firm - a greater quantity produced - to induce this firm to choose the passive strategy.

If $k$ is large enough, the discontinuity point will occur at or beyond the unconstrained Cournot duopoly equilibrium. In this symmetric model, the symmetric Cournot duopoly equilibrium will then result. This is shown in figure 3 . The condition then for the unconstrained symmetric Cournot duopoly equilibrium to obtain is that $k$ is large enough so that each firm will make greater profits in that equilibrium than it would playing the passive strategy, i.e., allowing the other firm to export the full capacity of the line into its own market and producing its best response to the resulting residual demand. Any additions to the line beyond this point will still change the best-response functions, but will not change the point at which they intersect, which determines the equilibrium. Thus, further increases to the line capacity are of no social value. The $k$ at which the unconstrained Cournot duopoly equilibrium will result clearly depends on the nature of demand. If we define $\pi(\cdot, \cdot)$ as the profits earned in a single market by the firm whose quantity is shown in the first argument given that the other firm produces, for that market, the quantity in the second argument, (i.e., $\pi\left(Q_{1}, Q_{2}\right)=Q_{1} P\left(Q_{1}+Q_{2}\right)-C\left(Q_{1}\right)$, where $P(\cdot)$ is the inverse demand function for a single market and $C(\cdot)$ is the firm's total cost function), then we have:

Result 3 The threshold transmission line capacity that will result in the symmetric unconstrained Cournot duopoly equilibrium, $k *$, is determined implicitly by

$$
\pi\left(Q_{m}^{-}, k *\right)=\pi\left(Q_{c}, 0\right),
$$

The left-hand side of [1] is the profits to a single firm from the passive strategy and the right-hand side is the profits to a single 
firm from the unconstrained Cournot duopoly equilibrium. The right-hand side is independent of $k$. The lefthand side is the profits earned from optimizing along a demand curve that is a leftward shift of $k$ units from the market demand curve, so the lefthand side is monotonically decreasing in $k$. At $k=0$ the lefthand side would be greater than the righthand side and at $k=\infty$ the lefthand side would equal zero, so there is some $k=k *$ that equalizes the profits of these two strategies. For any $k \geq k *$ the unconstrained Cournot duopoly equilibrium results. At any $k<k *$, the unconstrained Cournot duopoly quantity is not a best response for either firm. In fact, we can now strengthen result 1 and state the following.

Result 4 The only possible pure strategy equilibrium to this game is the unconstrained Cournot duopoly equilibrium. If $k<$ $k *$, no pure strategy equilibrium will exist.

The absence of a symmetric pure strategy equilibrium when $k<k *$ is easy to see: If outputs are symmetric, the line is uncongested. But, if the line is uncongested and a firm is producing less than the $Q$ that would be its best response quantity in a unified market, then the firm has an incentive to expand output. That is, if both firms were producing some $Q<Q_{c}$, and the line was uncongested, either firm would want to increase its output towards (and beyond) $Q_{c}$. The proof that there is no asymmetric pure strategy equilibrium for this model involves showing that it is never an equilibrium for one firm to play the passive strategy and the other to produce $2 k$ more. This is done in appendix $\mathrm{A}$.

\subsection{Transmission Lines and Unconstrained Cour- not Duopoly Equilibria}

An interesting and potentially very important area for study is the size of the line necessary to yield the unconstrained Cournot 
duopoly equilibrium. We have investigated this question with constant marginal cost and linear or constant elasticity demand. The results are quite consistent between these two functional forms. We discuss first the linear demand case.

Consider one example to demonstrate the possible outcomes as the line capacity changes. In this simple example, the demand in each of two markets is $Q=10-P$ and the marginal cost of production is constant at zero. With no line, each firm will produce 5 units of output and the price in each market will be 5 . With a very high capacity line between the markets, there will be no transmission constraint and the firms will compete to the Cournot duopoly equilibrium in the combined market. In this example, the Cournot duopoly outcome involves each firm producing 6.667 units and a market price of 3.333 results. Each firm then earns profits of 22.22 .

Using these results and equation [1] above, we can calculate that the Cournot duopoly outcome is achieved for any line with $k \geq 0.57$ (approximately). With $k=0.57$, either firm would be indifferent between producing 6.667 units and producing 4.715, the passive strategy response, given that the other firm is producing 6.667 units. At any larger $k$, each firm would strictly prefer the Cournot equilibrium to playing the passive strategy. The Cournot outcome results when the line capacity is about $12 \%$ of the monopoly output in either market $\left(k^{*} \approx .12 Q_{m}\right)$ and is only about $17 \%$ of the total increase in output in the two markets that results from building the line $\left(k^{*} \approx .17\left(2 Q_{c}-2 Q_{m}\right)\right)$. Since selection of quantity and price units is arbitrary, it is easy to demonstrate that these ratios are the same for any linear demand with constant marginal cost. As pointed out earlier, if such a line were built, no power would flow on it, as the equilibrium would be symmetric.

We also have investigated the general constant elasticity demand function $Q=A P^{\epsilon}$ with constant marginal cost, $M C=m$, for a range of values of $A, m$, and $\epsilon$. For each case, we calculated the same ratio as above, in which the numerator is the size of 
the line necessary to achieve the unconstrained Cournot duopoly outcome and the denominator is the increase in output associated with a change from separate monopolies to unconstrained Cournot equilibrium when the two markets are fully integrated. The ratio is independent of $A$ and $m$. It ranges from about $8.3 \%$ when $\epsilon=-1.1$ to $14.3 \%$ when $\epsilon=-10$, increasing monotonically as $\epsilon$ increases in absolute value.

\section{Thin Lines and Mixed-Strategy Equi- libria}

We have shown that there is a threshold level of capacity, above which two otherwise isolated markets are effectively merged. It remains to examine what happens to prices and output levels for line capacities that are below the threshold level that induces the Cournot duopoly result. In this section we examine competitive behavior for markets connected by these relatively "thin" lines.

By Nash's theorem, the fact that a mixed strategy is a firm's best response implies that all of its pure components are equally profitable. So we have found a Cournot-Nash equilibrium if all of each player's $q$ 's are equally profitable and are more profitable than any other $q$, holding constant the opponent's strategy.

Even without finding the actual mixed-strategy CournotNash equilibria, it seems it seems likely that the expected price will decline as $k$ increases from zero. With a very thin line, for instance, the expected price must be very close to the monopoly level. If it were not, then either firm could improve its expected profits by simply admitting imports of $k$, and playing the passive strategy as a pure strategy. With $k$ near $k *$, the lower bound on price provided by the passive strategy is much weaker and the mixed strategy is more likely to result in a lower expected price.

The difficulty with finding the Cournot-Nash equilibrium in this particular model is that each player can choose from an 
infinite number of different pure strategies ( $q$ 's). All that we can do numerically is approximate this infinite set of $q$ 's with a few hundred possible values, say $q=\{0,0.1,0.2, \ldots 10\}$. But even with $100 q$ 's the vector that gives the probabilities of playing each particular $q$ will be a 100 dimensional vector. Searching over such a space is not feasible since even with a few possible probability values the set of possible strategies runs into the billions.

Instead of solving for mixed strategies analytically, we take an alternative approach known as "fictitious play." To create an efficient search algorithm we follow a learning procedure that might be applied by two players actually playing this game repeatedly. ${ }^{12}$ The algorithm is described in Appendix B. Once a possible Cournot-Nash equilibrium is found with this algorithm, it is straightforward to check numerically that it is in fact such an equilibrium. ${ }^{13}$

Using this method, we examined market outcomes for various line capacities using two different demand models. The first model uses a linear demand function of $q=10-p$ and has suppliers with a constant marginal cost of zero. The second model assumes demand with a constant elasticity ${ }^{14}$ of -2 and suppliers with constant marginal costs equal to one.

The results from each of the models further support the analytical conclusions of the previous sections. Line capacity has a clear and pronounced effect on the output of both competitors. Figures 4 and 5 show the changes in expected prices in each market for the demand functions we modeled. In each of the cases, increases in line capacity cause a monotonic decline in the expected market price and a monotonic increase in

\footnotetext{
${ }^{12}$ See Fudenberg and Levine, forthcoming, chapter 2, for a full description of fictitious play.

${ }^{13}$ We do this by establishing that the profits are equal for the quantities over which a firm is randomizing and greater than at all other quantity choices.

${ }^{14} q=a p^{-2}$ where $a$ is set so that $q=5$ when $p=5$
} 
expected quantities produced up to the point that the unconstrained Cournot duopoly equilibrium is reached. Beyond the line capacity that yields the unconstrained outcome, further increases have no effect.

In both of these models, we find that small increases in line capacities can yield output increases much larger than the added line capacity. This is consistent with the analytic conclusion that the line capacity necessary to completely merge the two markets is relatively small compared to the added output that such a merging produces. In both models, even small lines produced big benefits. In fact, the marginal effect of increased line size appears generally to be greatest when the line is very thin, though the slope does not appear to change monotonically.

With linear demand and a transmission line that isn't very thin, the mixed-strategy equilibrium that obtains from the search algorithm consists of mixing over two strategies. ${ }^{15}$ As the line capacity declines, the difference between the two quantities over which the firm mixes in equilibrium also declines. At some line size (in the linear demand case, at about one-fifth of the line size that yields the unconstrained outcome), the number of distinct quantities over which the firm mixes in its equilibrium strategy rises to three. With still thinner lines, the number rises further. With constant elasticity demand, the search algorithm yielded similar results except that instead of two distinct quantity choices there appear to be two distinct quantity regions; a bimodal distribution with positive probability in only two narrow regions, but not so narrow that they can clearly be attributed to computer approximation.

\footnotetext{
${ }^{15}$ In some cases, the program indicated equilibrium strategies including two prices that were adjacent or nearly adjacent in the grid over which the program searched. We considered these to be a single point in the mixing distribution.
} 


\section{$5 \quad$ Extensions and Generalizations}

\subsection{Dominant Firms with Fringe Suppliers}

Pure monopolies are quite rare, of course, even in the formerly regulated electricity generation business. It is worth noting, however, that the analysis we have presented applies equally well to two symmetric markets in which each includes a dominant firm and a competitive, price-taking fringe. In that situation, the demand functions analyzed above are the residual demand functions in each market, i.e., market demand minus the quantity that the fringe will produce at each price. We have assumed efficient arbitrage between markets throughout the analysis market prices differ only if the line between the two markets is congested - so the presence of the additional competition in each market has no further effect on the relationship between the markets.

\subsection{The Effect of Line Losses}

Thus far, we have assumed that the transmission line is lossless. In reality, of course, some electricity may be dissipated as heat in the transmission process. The proportion of power lost in this way increases with the load on the line and can be as great as $5-10 \%$ of the flow on the line. Surprisingly, however, if the line if sufficiently large to support the unconstrained pure-strategy Cournot equilibrium in the absence of line losses, then such line losses could have no effect on the unconstrained Cournot equilibrium or the capacity of the line necessary to attain it.

To see why line losses may be irrelevant to the analysis, note first that there is no flow on the transmission line in the symmetric unconstrained Cournot equilibrium, so costs would not be directly affected by line losses. As we have demonstrated, however, the unconstrained Cournot equilibrium obtains only when the 
line is of sufficient size that each firm earns higher profits than it would earn from playing the passive strategy. More generally, for the unconstrained (no-losses) Cournot duopoly equilibrium quantities to be an equilibrium in the presence of line losses, each firm must be at its global profit maximum.

A standard approximation for total line losses is $L=r f^{2}$, where $f$ is the flow on the line and $r$ is a constant based on the physical properties of the line. ${ }^{16}$ This implies that marginal loss is $l=2 r f$, which equals zero when there is no flow on the line. If $r$ is very large, a reduction of output by one firm will induce a low quantity of imports from the other market and will thus increase profits. If $r$ is very near zero, a reduction of output by one firm from its Cournot quantity will induce nearly as great a quantity of imports from the other market as with no losses and will thus decrease profits. ${ }^{17}$

Thus, ignoring the transmission constraint $(k)$, if $r$ is sufficiently small, $Q_{c}$ will be a global profit maximum for one firm given that the other firm produces $Q_{c}$. This will be true for the $\tilde{Q}<Q_{c}$ that would cause the line to have flow equal to $k$. For any quantity less than $\tilde{Q}$, the line will be congested into the firm's market. At that point, losses become irrelevant, because the only effect they could have on a firm that is considering reducing its output is in lowering the resulting flow into its market. Thus, so long as losses are small enough that a firm reducing its output earns lower profit at any quantity in $Q_{c}>Q>\tilde{Q}$ than

\footnotetext{
${ }^{16}$ See Schweppe, 1988, appendix D.

${ }^{17}$ There is also a closely related issue of whether the Cournot equilibrium quantities are local profit maxima in the presence of non-zero losses. From the Cournot equilibrium, if one firm reduces its quantity, that has only second order effect on its unconstrained profits and only second order effect on the line losses incurred on imports from the other market. So, whether the no-losses equilibrium quantities are also local profit maxima for the firms when there are line losses, will depend on a comparison of the second derivative of the losses function $(2 r)$ with the second derivative of the firm's profit function. For a sufficiently small, but still strictly positive, $r$, the Cournot equilibrium quantities in the absence of losses are still local profit maxima with losses.
} 
it earns at $Q_{c}$, losses will be irrelevant to the analysis of the passive strategy and the to the calculation of line capacity the yields the Cournot equilibrium, $k *{ }^{18}$

\subsection{One Rival Can Be More Competitive Than Many}

An intriguing result emerges when we compare the outcome from our two-monopoly model with the outcome when one of the markets is already perfectly competitive before the line is built. For example, if the demands in each market are still identical, $P=10-Q$, and marginal cost is constant at zero, then the competitive market will have a price equal to zero both before and after the line is built. If a line of $k=0.57$ is built (the capacity that yields the unconstrained Cournot duopoly equilibrium), then the previous monopolist will produce its best response when an inflow of 0.57 congests the line, which is to produce $q=4.715$, the passive strategy. The total quantity in the previously monopolized market would then be 5.285 , much less than the Cournot duopoly quantity that resulted in each market when the same size line was used to connect two previously monopolized markets. That is, the competitive effect of this line on a monopoly market is greater if the market at the other end is also a monopoly than if it is competitive.

The reason for this surprising result is that a more aggressive strategy deters imports when the potential importer is also a monopolist in its home market, while it has no such effect when there is a competitive market at the other end of the line. Thus, with a competitive market at the other end of the line, the Cournot duopoly outcome is not a possibility, and the firm will

\footnotetext{
${ }^{18}$ This assumes that the line losses do not actually lower the capacity of the line to deliver power from one end to the other. To the extent that the line losses lower the capacity to a proportion $\gamma$ of the capacity without line losses, then the line must be $1 / \gamma$ of its previous size to attain the unconstrained Cournot equilibrium.
} 
always choose to play the passive strategy, optimizing along the residual demand curve that results when the line is congested with inflowing electricity.

Of course, the result does not hold for all size lines. If the line is sufficiently large ( $k=10$ in the linear demand example), then both markets would be driven to the competitive price. Still, if the line is smaller than is necessary to induce an output increase in the monopolized market equal to the output increase when it expands to the Cournot duopoly equilibrium, then a customer in a monopolized market will benefit more from having a monopoly market at the other end of the line than from having a competitive market at the other end. In the present example, if market $N$ were monopolized, then any line smaller than $k=$ 3.333 would yield greater benefits to the consumers in market $N$ if market $S$ were also monopolized than if market $S$ were competitive. This doesn't even take into account the fact that it would also benefit the customers in a monopolized $S$ market while, it would have no effect on a competitive market $S$.

\subsection{Transmission Capacity under Regulation and Deregulation}

The transmission capacity that now exists in most of the U.S. was built to provide the cost-arbitrage and reliability functions described earlier. It was not built to augment competition among power generators. Our analysis leads immediately to the question of how the socially optimal transmission capacity under regulation compares to the social optimum when power generating markets are deregulated. Clearly, it is difficult to make such a theoretical comparison without characterizing the regulation in detail. We will assume here that regulation is optimal, first-best regulation of price, location of generation, and transmission capacity.

The symmetric markets that we have studied thus far demonstrate that situations can exist in which the optimal transmis- 
sion capacity under regulation would be less than for competition. With symmetric markets, transmission lines fulfill no cost-arbitrage function. The value of transmission for reliability is likely to be just as great under competition as regulation. Furthermore, if each firm produces from a portfolio of generators, as is generally the case, the value of transmission lines in providing reliability diminishes rapidly and is unlikely to justify transmission lines that are of significant capacity compared to market outputs.

Ignoring reliability considerations, there is no value to a transmission line in the symmetric market case; the optimal line capacity would be zero. In a deregulated market, we have demonstrated that the marginal benefit to transmission capacity could be quite large. Of course, the socially optimal transmission capacity would still depend on the cost of constructing transmission, but in this case it clearly will be (weakly) greater than under regulation.

Unfortunately, even ignoring reliability issues, one cannot make a general statement that the marginal value of transmission is greater in a deregulated environment. For an example of a situation in which the marginal value of transmission would be greater under regulation, consider two markets with identical demand in which the single producer in one market has slightly lower constant marginal costs than the single producer in the other market. From the previous sections (and made explicit in section 5), it is clear that there is some line size that will support a Cournot duopoly equilibrium and that any transmission capacity beyond that $k *$ has no social value. This will be less than the $k$ that would be necessary for the low-cost producer to serve all demand in both markets, which would be the case under optimal regulation that sets price equal to the low cost firm's rnarginal cost. For transmission capacity above $k *$, but below the quantity consumed in the market of the high-cost producer, the marginal social value would be greater in a regulated market. Thus, an optimally regulated market could yield greater transmission capacity than would be optimal in a deregulated 
market. $^{19}$

\subsection{Bertrand Competition}

We have thus far considered only the case in which the firms compete in quantities. ${ }^{20}$ This seems reasonable for competition in the long run, because firms must make capacity decisions and thus commit to output, or at least an upper bound on output. ${ }^{21}$ Even in the short run, firms will have to commit to which plant units they will operate before they bid for business. Thus, Cournot competition may be a reasonable approximation of the game played between firms. It is possible, however, that the unit-commitment decision will still leave a dominant firm with significant output flexibility in the short-run. ${ }^{22}$ It is therefore worth considering the competitive effect of transmission lines when there is an unconstrained dominant firm at each end of the transmission line and these firms compete in prices.

A Bertrand analysis of this setting, however, is necessarily somewhat non-standard. With both firms recognizing a quantity constraint in transmission, their behavior in choosing prices will differ from the standard Bertrand model. Still, in this setting, the Cournot analysis and intuition carries over fairly easily.

\footnotetext{
${ }^{19}$ Of course, this comparison is based on the assumption of Cournot behavior in a deregulated market. The outcomes, and the value of transmission, would be the same under optimal regulation and perfect competition.

${ }^{20}$ Oren (1996), and Cardell, Hitt, and Hogan (1996) also assume Cournot behavior to examine other questions concerning market power in electricity networks.

${ }^{21}$ Kreps and Scheinkman (1983) have shown that under certain assumptions capacity choices followed by Bertrand price competition is identical to Cournot behavior. See Davidson and Deneckere (1986) for a discussion of the restrictions on the Kreps and Scheinkman result.

${ }^{22}$ If more than one firm in each market is not capacity constrained and the firms compete in prices, the equilibrium price will be equal to marginal cost.
} 
Again, we will assume that the markets and the firms are identical. ${ }^{23}$ If there is no transmission line between the markets, then obviously the monopolists in each market will exercise their full market power. If the line is sufficiently large, then the standard Bertrand equilibrium will obtain: the markets will be fully integrated and price will be equal to marginal cost.

The line that yields the Bertrand equilibrium, however, would have to be quite large; it would have capacity equal to the quantity demanded in either market when price is equal to marginal cost. To see this, recall that price is equal to marginal cost in the Bertrand equilibrium, so firms earn zero operating profits. Thus, if playing a passive strategy - e.g., firm $s$ charging a sufficiently high price to allow firm $n$ to export the full capacity of the line into market $S$ - leaves any residual demand for $s$ to serve at a price above $M C$, then $s$ can make higher profits optimizing along a residual demand curve after $n$ congests the line than playing the unconstrained Bertrand strategy. Only if $n$ can force the price in $S$ down to $M C$ (or $s$ can force the price in $N$ down to $M C$ ) will the Bertrand outcome obtain. This requires a line equal to the quantity demanded in either market when price is equal to $M C, k *=Q(M C)$, where $Q(\cdot)$ is the demand function in a single market.

If the line capacity is less than this $k *$, it is clear immediately that there will not be a pure strategy symmetric equilibrium with both firms charging the same price; in that situation either firm could increase profits by cutting price $\epsilon$ and thereby selling all quantity in its own market and $k$, the capacity of the line, in the other market. Instead, a firm would have to choose between one of two possible actions: (1) undercut the other firm's price and sell all quantity in its own market and $k$ in the other market or (2) allow the other firm to congest the line with exports and optimize along the residual demand that is left. Option (1) cannot lead to an equilibrium since it causes a downward spiral

\footnotetext{
${ }^{23}$ To ensure existence of a Bertrand equilibrium, we must now also assume constant marginal costs of production for both firms.
} 
to $P=M C$, which is not an equilibrium when $k<k *$ by the argument of the previous paragraph. Option (2) would be preferred to option (1) by a firm only if (2) involves charging a higher price. But if firm $s$ plays the passive strategy and raises its price, then $n$ will immediately raise its own price to $\epsilon$ less than $P_{s}$ and still congest the line into $S$. If their prices are nearly equal, however, $s$ is better off choosing option (1). This will restart the price cutting until one firm again prefers the passive strategy. Thus, as with Cournot, there will be no pure strategy equilibrium with $k<k *$. In this case, however, $k *$ is probably much larger relative to the increase in output. There still will be at least one mixed-strategy equilibrium with a line of $k<k *$ and, for the reasons described in section 4, it seems likely that the expected price will decline as $k$ increases from zero.

\section{Asymmetric Firms and Markets}

So far, we have analyzed symmetric firms and markets, which have the special property that identical pure strategies will produce no flow on the connecting line. While the analysis of symmetric markets is useful as an illustration, interesting real-world applications, including the one in the following section, will invariably be asymmetric to some extent. Fortunately, the intuition and analytical approach developed thus far carries over to the analysis of asymmetric markets.

With a low-capacity transmission line and symmetric markets, we were able to rule out any pure strategy equilibrium; we showed that the unconstrained Cournot equilibrium was not supportable and that no other pure strategy equilibrium was feasible. When markets are asymmetric, however, a pure strategy equilibrium is likely to result with a very thin line.

Whether a pure strategy equilibrium exists as line size approaches zero depends on one simple criterion: if the monopoly 
equilibria in the two markets produce the same price, then as the capacity of a transmission line approaches zero, there will be only a mixed-strategy solution. If the markets produce different monopoly prices, there will be a pure-strategy solution for a sufficiently thin line: power will be shipped from the low-price to the high-price market until the line is congested. The firm in the high-price market will play the passive strategy and the firm in the low-price market will play the aggressive strategy.

Virtually any real pair of markets will embody asymmetries that result in different monopoly prices and thus will have such a pure strategy "passive/aggressive equilibrium" for sufficiently small lines. ${ }^{24}$ This is illustrated in figure 6 for two markets in which $N$ is larger than $S$ and two firms, $n$ and $s$, that have equal and constant marginal costs. ${ }^{25}$ As the capacity of the line increases, exports from the low-price market, $S$, increase. This shifts rightward the demand that $s$ faces in market $S$ and drives up the price in $S .{ }^{26}$

As exports into $N$ increase, firm $n$ will cut back production, but by less than the increase in imports to $N$ and so the price in market $N$ will fall. As line capacity continues to increase, eventually a point must be reached at which a pure-strategy unconstrained Cournot duopoly equilibrium can be supported.

\footnotetext{
${ }^{24}$ There are some asymmetric examples that produce mixed strategies in the thin-line limit. For instance if one market is just a scaled-up version of the other, the monopoly prices will be the equal. Additionally, there are examples where the two markets have different shaped cost and demand functions but still have the same monopoly price. These too produce mixed strategies in the thin-line limit.

${ }^{25}$ We continue here to assume no line losses. Unlike the symmetric case, line losses will affect the asymmetric case because there will be flow in equilibrium. In particular, line losses will change the unconstrained Cournot equilibrium by lowering the output of the firm that would be a net exporter in a lossless framework and raising the output of the firm in the importing market.

${ }^{26}$ The markets illustrated in figure 6 have different demands, while the firms illustrated have equal costs, so the unconstrained Cournot equilibrium is still symmetric.
} 
As the line approaches the size that supports the unconstrained pure-strategy equilibrium, one of two possibilities may arise.

Result 5 Consider asymmetric markets, $N$ and $S$ with monopoly producers $n$ and $s$, respectively. Assume that $P_{m}^{s}<P_{m}^{n}$. For a sufficiently small line, a pure-strategy passive/aggressive equilibrium where the line is congested with flows from $S$ to $N$ will exist. As the line capacity increases, at least two outcomes are possible.

1. There will be a range of line capacities for which no pure strategy equilibrium exists. This range will extend up to the point where the line capacity is large enough to support the unconstrained Cournot equilibrium.

2. A pure-strategy passive/aggressive equilibrium will exist for all ranges of line capacity up to the capacity that supports the unconstrained Cournot equilibrium. When the line capacity is just large enough to support the unconstrained solution, $k=$ $k *$, and for some range of $k>k *$, two pure-strategy equilibria will exist: the unconstrained Cournot equilibrium and the passive/aggressive equilibrium with the line congested with flows from $S$ to $N{ }^{27}$ For capacity greater than some $\bar{k}$, where $\bar{k}>k *$, only the unconstrained pure-strategy Cournot equilibrium will exist.

Case 2, which we call the "overlap" case will arise if and only if at $k=k *$, the unconstrained Cournot equilibrium output of firm $s$ is less than $s$ 's best response when firm $n$ plays the passive strategy, $Q_{m}^{s+}>Q_{c}^{s}$.

In the following subsection, we prove by example the existence of these two cases. The examples also demonstrate the intuition behind the necessary and sufficient condition for the overlap case. We prove this condition in appendix A. Case 1,

\footnotetext{
${ }^{27}$ In this case where two pure-strategy equilibria will exist, there will also be a mixed-strategy equilibrium (Fudenberg and Tirole, 1991, pp. 479-480). We have not solved for this equilibrium.
} 
the non-overlap case is illustrated in figure 7. After a certain line capacity is reached, there again is a region where only mixed strategy equilibria exist up to the threshold line capacity that induces the producer in $N$, the higher-price market, to switch from playing its passive strategy to playing its unconstrained Cournot responses. In the overlap case - which seems to arise in more asymmetric markets - there is at least one pure-strategy equilibrium for all line capacities. Unlike the symmetric case, $n$ is content to play its passive strategy when $s$ is producing $Q_{m}^{s+}$, $s$ 's profit-maximizing output when it is congesting the line to $N$. In fact, even when the line capacity is large enough that firm $n$ would play an unconstrained Cournot response to $s$ 's unconstrained Cournot equilibrium quantity, $n$ would still prefer to allow the line to be congested into its market if its opponent maintains its output at $Q_{m}^{s+}$.

Thus, although the assumption of asymmetry does lead to a qualitative change in our analysis, it does not fundamentally change the picture. Increasing line strength gradually increases competition, and can lead through a region of mixed strategies to a standard Cournot duopoly equilibrium.

\subsection{Examples of Asymmetric Market Equi- libria}

It is straightforward to demonstrate situations where each of the two cases in result 5 may arise. For an example of the first case, where there exists a range of $k$ for which no pure strategy equilibrium exists, consider the following two markets, $N$ and $S$, where demands are $Q^{S}=10-p$, and $Q^{N}=12-p$, and each market has one producer with cost function, $C^{s}(Q)=C^{n}(Q)=$ 0 . With no transmission line, the prices in $S$ and $N$ are 5 and 6 , respectively, and the outputs are 5 and 6 , respectively, for a total industry output of 11 . The Cournot equilibrium quantities are $\frac{22}{3}$ for each firm with a total industry output of $\frac{44}{3}$ and price 
of $\frac{11}{3}$, and a net flow on the line of 1 from $S$ to $N$. The profit of each firm in this equilibrium is $\frac{22}{3} \cdot \frac{11}{3}=\frac{242}{9}$ or about 26.89 .

The northern firm's profit. if a line of size $k$ is congested into its market is

$$
\pi_{n}\left(Q^{n}(k)\right)=p_{n}\left(Q^{n}+k\right) Q^{n}=\left(12-Q^{n}-k\right) Q^{n} .
$$

and the first order condition implies that $Q_{m}^{n^{-}}=6-\frac{k}{2}$, where $Q_{m}^{n^{-}}$is $Q_{m}^{-}$for firm $n$, giving profits from the passive strategy of

$$
\pi_{n}\left(Q_{m}^{n^{-}}(k)\right)=\left(6-\frac{k}{2}\right)^{2}
$$

The line capacity, $k$, that leaves the northern firm indifferent between the unconstrained Cournot and the passive strategy is therefore $\left(6-\frac{k}{2}\right)^{2}=26.89 \Longrightarrow k=1.6291 .^{28}$ For a line size slightly less than this, $k=1.6$ for instance, the unconstrained Cournot equilibrium is not achievable; firm $n$ would (just barely) prefer to play the passive strategy than to play its Cournot best response to $s$ producing its unconstrained Cournot quantity. But, if $n$ plays the passive strategy, $s$ will revert to selling its profit-maximizing quantity that congests the line, $Q_{m}^{s+}=5.8146$. This is less than $s$ 's Cournot quantity, 7.3333. As $s$ reduces its output, the passive strategy becomes less attractive to $n$. In this case, $n$ will jump to producing its Cournot best response to 5.8146 , which is 8.0927 . With the line unconstrained, however, $s$ will then respond with its Cournot best response of 6.9536, and the process will once again iterate towards the unconstrained Cournot equilibrium. Since, the line is just slightly below the level that can support the unconstrained Cournot, as s's output approaches its Cournot equilibrium quantity, and strictly before it equals that quantity, $n$ will once again revert to playing the passive strategy. No pure strategy equilibrium exists.

\footnotetext{
${ }^{28}$ Note that the line of $k=1.6291$ yields additional output of only 3.6666 , a ratio of about $2.25: 1$, in contrast to the nearly $6: 1$ ratio that we found with linear demand and constant marginal cost in the symmetric case.
} 
For an example of the second case, consider markets with the following demands: $Q^{N}=15-p, Q^{S}=15-4 p$ and again one producer in each market with $C^{n}(Q)=C^{s}(Q)=0$. If there is no transmission line, the monopoly quantities in the two markets are each 7.5 and the monopoly prices are $P^{N}=7.5$ and $P^{S}=1.875$. If there were a transmission line with no capacity constraint, then the Cournot problems for the two firms would be identical. In the resulting Cournot duopoly equilibrium, $Q^{n}=Q^{s}=10, P=2$ and each firm earns profits of $\pi=20$.

We now examine the market outcomes when the transmission constraint is binding. If firm $n$ plays the passive strategy, its profit as a function of the line capacity $k$ is

$$
\pi_{n}\left(Q_{m}^{n-}(k)\right)=\left[p_{n}\left(Q^{n}+k\right)\right] Q^{n}=\left(15-Q^{n}-k\right) Q^{n}
$$

The first order condition implies that $Q_{m}^{n-}=7.5-\frac{k}{2}$, giving profit for firm $n$ when it plays the passive strategy of

$$
\pi_{n}\left(Q_{m}^{n-}(k)\right)=\left(7.5-\frac{k}{2}\right)^{2}
$$

The line capacity, $k$, that leaves the northern firm indifferent between the unconstrained Cournot duopoly equilibrium and the passive strategy is therefore $\left(7.5-\frac{k}{2}\right)^{2}=20 \quad \Longrightarrow \quad k=6.057 .{ }^{29}$ For a line size slightly less than this, $k=6$ for instance, the unconstrained Cournot duopoly equilibrium is not achievable; firm $n$ would (just barely) prefer to play the passive strategy than to play its Cournot best response in response to $s$ producing its unconstrained Cournot quantity. At $k=6$, however, there is a passive/aggressive equilibrium in which $s$ produces $Q^{s}=10.5$ of which 6 is exported to $N$ and firm $n$ responds by producing $Q^{n}=4.5$.

\footnotetext{
${ }^{29}$ Note that the line of $k=6.057$ yields additional output of only 5 , a ratio of $0.825: 1$.
} 
At $k=6.057$, the unconstrained Cournot duopoly equilibrium is feasible. From that equilibrium, if the north firm were to reduce its output from its Cournot quantity of 10 to its passive strategy optimum of $7.5-\frac{6.057}{2}=4.472$, the line would become congested with flow from $S$ to $N$. Given that the line is congested, the optimum output for $s$ would be $Q_{m}^{s+}=\frac{15+k}{2}=$ 10.528 .

Unlike in case 1, if firm $n$ jumps from the unconstrained Cournot duopoly equilibrium to playing the passive strategy, firm $s$ 's best response in this case is to increase its output from the quantity it produces in the unconstrained Cournot duopoly equilibrium. This reinforces $n$ 's incentive to play the passive strategy. Thus, when $k=6.057$, the critical line size to support the unconstrained Cournot duopoly equilibrium, there is a also a passive/aggressive equilibrium. In this equilibrium, firm $n$ produces $Q^{n}=4.472$, and firm $s$ produces $Q^{s}=10.528$, the line is congested with flows from $S$ to $N$ of 6.057 . The result is a price in the north of $P^{N}=4.471$ and in the south of $P^{S}=$ $2.632 .^{30}$ This sort of outcome with two pure-strategy equilibria is illustrated in figure 8 .

As the line size increases beyond $k=6.057$, both the unconstrained and the passive/aggressive equilibria are possible until the line expands to about $\bar{k}=6.36$, the line size at which the passive/aggressive equilibrium disappears. At any line size above $\bar{k}$, firm $n$ 's profit from playing the passive strategy, which congests the incoming line, are smaller than the profit of playing the unconstrained Cournot best response. ${ }^{31}$

\footnotetext{
${ }^{30}$ If the passive/aggressive pure-strategy equilibrium obtains, then total output is unchanged from the outcome with no transmission line (with linear demand and constant marginal cost). There would, however, still be a positive total surplus effect from building the line: output would be reallocated from $s$, where it has lower value on the margin, to $n$. This is reflected in the fact that the line causes $P^{S}$ to increase and $P^{N}$ to decline.

${ }^{31}$ The profit of $n$ playing its unconstrained Cournot best response to the aggressive firm playing $Q_{m}^{s+}$ is $\pi=18.66$. Comparing this to the profit from playing the passive strategy, $\left(7.5-\frac{k}{2}\right)^{2}$ and solving for $k$ gives $\bar{k}$.
} 
Two pure-strategy equilibria exist for some line sizes in case 2 , but not in case 1 , because in case 2 , when $n$ switches from the unconstrained Cournot equilibrium to its passive strategy, firm $s$ responds by increasing its own output. An increase in $s$ 's output decreases the profitability for $n$ of playing its unconstrained Cournot best response, reinforcing its decision to play the passive strategy. In contrast, in case 1, s's output fell in response to $n$ playing the passive strategy, thereby inducing $n$ to deviate from the passive strategy. This illustrates the necessary and sufficient condition expressed in result 5.

\section{The California Electricity Market: An Empirical Example of the Strate- gic Use of Congestion}

As mentioned earlier, this paper was motivated largely by observations about the deregulation of California's electricity market. It is widely recognized that California's electricity market will sometimes be divided into at least two distinct geographic regions; northern and southern California. These two regions are connected through what is known as transmission path 15 , which consists of several transmission lines that connect the Midway and Vincent substations (WSCC, 1996). Currently, Pacific Gas \& Electric (PG\&E) is the dominant supplier north of path 15 and Southern California Edison is the largest electricity producer south of the path 15 constraint. ${ }^{32}$ Peak demand in the

\footnotetext{
${ }^{32} \mathrm{PG} \& \mathrm{E}$ owns approximately $2700 \mathrm{MW}$ of generation capacity that is located south of the Path 15 demarcation. Pace (1996) states that PG\&E currently holds the transmission rights to between 2500 and $3000 \mathrm{MW}$ over Path 15. Around $2000 \mathrm{MW}$ of this is for the Diablo Canyon nuclear plant, which will be under a separate regulatory agreement and will therefore not receive market-based rates. While the actual control of transmission capacity in California will be held by an Independent System Operator, any transmission congestion revenues will flow back to the original holders of the
} 
south is more than double the peak in the north, ${ }^{33}$ but there is also much more generation capacity owned by smaller firms located south of this constraint (see Table 1).

In section 5 , we noted that the presence of price-taking fringe firms in either or both markets would not alter the analysis. This is also true if those fringe firms are in fact in other regional markets that are connected to one of the dominant firm's market through a transmission path. Essentially, the models of the previous sections are directly applicable to markets where the dominant-firm regions are connected to competitive regions, and to each other, via a radial or linear network. There are also many markets that do not fit this description exactly, but under certain conditions resemble such a configuration closely enough that the intuitions developed from these models can still apply. California is one such market.

\begin{tabular}{|c|c|c|c|}
\hline Region & $\begin{array}{c}\text { September } \\
\text { Peak Demand }\end{array}$ & $\begin{array}{c}\text { Capacity of the } \\
\text { Largest Firm }\end{array}$ & $\begin{array}{c}\text { 'Fringe' } \\
\text { Capacity }\end{array}$ \\
\hline \hline $\begin{array}{c}\text { Northern } \\
\text { California }\end{array}$ & $16236 \mathrm{MW}$ & $13662 \mathrm{MW}$ & $8623 \mathrm{MW}$ \\
\hline $\begin{array}{c}\text { Southern } \\
\text { California }\end{array}$ & $37884 \mathrm{MW}$ & $14013 \mathrm{MW}$ & $16971 \mathrm{MW}$ \\
\hline
\end{tabular}

Table 1: The California electricity market $^{34}$

transmission rights. It is intended that this congestion revenue will reflect the price differences between the regions connected by the transmission links. Thus the remaining unregulated generation facilities located south of Path 15, when combined with this congestion revenue, will in theory earn the northern California price. We therefore include the revenues from this capacity in the profit calculation of PG\&E.

${ }^{33}$ The Path 15 demarcation in fact divides PG\&E's service territory into a larger northern portion and a smaller southern portion. The demand estimates below reflect the actual expected location of the demand

${ }^{34}$ Demands are CEC forecasts for the year 2001. Southern California fringe capacity includes $2703 \mathrm{MW}$ of PG\&E owned capacity located south of Path 15. 
The reader may note from table 1 that Southern California must import to meet its peak demand needs. In fact this region is connected with the desert southwest over transmission paths with capacities over $11,000 \mathrm{MW}$ and with the Pacific northwest through a direct DC link with a capacity of $2990 \mathrm{MW}$. In the high demand months of August through October, southern California is usually importing considerable power from the desert southwest. Since there is relatively little spare hydro capacity in the Pacific northwest during these months, this region does not usually export to California during this period. Although table 1 might lead one to believe that congestion of north-to-south flows would be the primary concern, in the fall and winter just the opposite is in fact true. Almost half of PG\&E's capacity is hydro-electric generation. Due to limits on the total water that can be released from reservoirs, much of this capacity is not utilized during off-peak hours. During these non-peak hours, path 15 can become constrained with flows from southern California into the north.

Most analysts agree that PG\&E, in its current form, has significant potential market power when the northern California region is isolated from its neighbors. ${ }^{35}$ The interesting question, however, is how often is this isolation likely to arise. It is in addressing this question that the analysis of the previous sections comes into play. While it would be tempting to simply calculate the flows that would occur in the absence of the Path 15 constraint and then see if the constraint is violated, the model we have presented indicates that this would fail to capture the potential for strategic congestion of the line. ${ }^{36}$

\footnotetext{
${ }^{35} \mathrm{PG} \& \mathrm{E}$ has put forth a plan to spin off half of its gas-generator production to lessen market power concerns.

${ }^{36}$ Some studies have relied upon historical information on the power flows over the various transmission paths (see, Pace 1996). However, these data were generated by firms operating in a tightly regulated environment. The incentives faced by these firms after the transition period to a deregulated industry will be significantly different, and there is no reason to believe that this change in incentives would not alter the usage of tramsmission facilities.
} 
In related work examining the potential for market power in California after deregulation, Borenstein and Bushnell (1997) develop a Cournot-fringe firm simulation of the Californian and neighboring electricity markets. Here we adapt that model to examine the potential for congestion of path 15, the primary north-south link in California. As indicated above, we consider only the two largest suppliers in California to be strategic players, and treat the other electricity producers in California, as well as any out-of-state firms exporting power to California, as price-taking fringe firms. ${ }^{37}$

We focus on two months, September and December, in which there is no significant surplus capacity available for export into California from the Pacific northwest. In these months the $\mathrm{Pa}$ cific northwest is usually importing power from southern California and the desert southwest. We assume that in these months the import demand of the northwest region absorbs any additional power that would flow directly from southern California and that this power is therefore not available for shipment back into northern California via Oregon. Thus the only significant transfer capability between southern and northern California is over path 15 .

We use a constant elasticity demand curve of the form $q(p)=$ $x p^{-\varepsilon}$ to model demand. The simulations presented here use a value of $\varepsilon=0.1$ for the elasticity of demand. ${ }^{38}$ The constant $x$ is set such that the demand curve in the peak hour intersects the

\footnotetext{
${ }^{37}$ The non-Californian western electricity markets were divided into three regions, the Pacific northwest, desert southwest, and Mexico. It was assumed that out-of-state firms were responsible for serving their own loads before exporting any surplus capacity to California. See Bushnell and Borenstein (1997) for a detailed specification of the assumptions and methods used in the simulation. This paper is available for downloading off the UCEI website at URL wwwucenergy.eecs. berkeley.edu/ucenergy/PDF/pwp044.pdf

${ }^{38}$ This elasticity is in the range of most estimates for short-run electricity demand. Examples similar to those presented below are easy to find for a wide range of assumed elasticities. We have also investigated the California market with using a linear demand assumption, though Borenstein and
} 
price-quantity point taken from the California Energy Commission's forecasted average price and peak demands for the year $2001 .^{39}$ The year 2001 was selected as a target date for the expiration of many of the regulatory distortions that will continue during the transition to competition. For each month, we simulated six demand levels starting with the peak hour, then the 150th highest demand level, and so on by increments of 150 down to the minimum demand level in each hour. Each simulation finds a static Cournot equilibrium that is assumed to be independent of the outcomes of the other hours simulated (those numbers in italics). ${ }^{40}$

We first find the Cournot equilibrium production levels of the two large firms under the assumption that path 15 has unlimited transfer capacity. Transfer capacity over this path is in fact about $3500 \mathrm{MW}$ in the south-to-north direction. ${ }^{41}$ An examination of the net flows over this path (table 2) reveals that flows never exceed $3500 \mathrm{MW}$ in September, but reached levels well over $4000 \mathrm{MW}$ in some hours of December. If one ignored strategic incentives to congest the line, one would assume that the northern and southern markets are never isolated from each other in the month of September. In December, one would find that the line is congested during the three highest demand hours simulated.

As we have shown, however, analysis of the potential for congestion between these two markets must account for the in-

Bushnell (1997) argue strongly that this is not as good an approximation to actual demand. The strategic congestion result can still obtain. An example is presented in appendix $\mathrm{C}$.

${ }^{39}$ The forecast average consumer price for 2001 was $9.3 \phi / \mathrm{kWh}$. We assume that $4.0 \% / \mathrm{kWh}$ of this is allocated to local transmission and distribution costs.

${ }^{40} \mathrm{Hydro}$ releases were 'scheduled' outside of the Cournot calculation according to a demand peak-shaving heuristic. The heuristic and its implications are discussed in detail in Borenstein and Bushnell (1997).

${ }^{41}$ Estimates of the actual transfer capacity have varied, and can depend upon load conditions elsewhere in the western U.S. The estimate of 3500 MW is in line with that used by Pace (1996). 
centives of the suppliers when they incorporate the transmission constraint into their profit calculations. ${ }^{42}$ We next calculated the profits made by PG\&E if it played the passive strategy (causing south to north congestion along path 15) and compared these profits to those that arise in the state-wide unconstrained Cournot equilibrium. This calculation reveals that in many of the hours examined, it is profitable for PG\&E to reduce output from its unconstrained Cournot level and induce congestion over path 15. Of the nine hours in Table 2 in which Path 15 would be uncongested without strategic behavior, five exhibit congestion (shown in bold) when PG\&E accounts for the possible strategic gains from congesting the line. In all of these cases, we found there to be a pure-strategy passive/aggressive equilibrium with path 15 congested with flows from south to north.

Table 2: Flows over path 15 assuming unlimited capacity

\begin{tabular}{lcccccc} 
Demand Level & Peak & 150 th & 300 th & 450 th & 600 th & 744th \\
\hline $\begin{array}{l}\text { September } \\
\text { path 15 flow (s-n) }\end{array}$ & -2577 & $\mathbf{2 4 5 4}$ & $\mathbf{2 5 7 1}$ & $\mathbf{3 3 7 3}$ & 653 & -1354 \\
$\begin{array}{l}\text { December } \\
\text { path 15 flow (s-n) }\end{array}$ & 4733 & 5020 & 4673 & $\mathbf{2 7 0 5}$ & $\mathbf{2 6 5 4}$ & 2378
\end{tabular}

We now focus on one specific demand level, the 450th highest demand hour in September, in order to examine the impact. of increased transmission capacity on this market. If there is unlimited transmission capacity along path 15 , south-to-north flows are $3373 \mathrm{MW}$. PG\&E can make higher profits in this hour if it reduces its output below its unconstrained Cournot levels and induces congestion. In order to test whether this leads to

\footnotetext{
${ }^{42}$ To do this, we simulated the northern California market on its own under the assumption that flows over path 15 were at their maximum. This northern market then becomes isolated, though still subject to a considerable amount of fringe supply capacity.
} 
an asymmetric pure strategy equilibrium, we must also examine the southern California market. We simulated this market under the assumption that there were exports from this region to the north equal to the flow capacity over path 15 .

One condition that must be met for there to be a pure strategy equilibrium where path 15 is congested with south-to-north flows is that the resulting price in the north must be greater than the price in the south. We must then calculate SCE'S output level in the southern California plus export market. Although PG\&E prefers an outcome where path 15 is constrained to the unconstrained Cournot equilibrium, it is possible that PG\&E, when faced with SCE's optimal response to a passive, congestion-inducing output by PG\&E, may find it more profitable to increase output and decongest the path. Such a scenario would imply that only mixed-strategy equilibria are possible for a path of this particular capacity. If instead PG\&E still prefers to play its 'passive' strategy in response to the 'aggressive', exporting output by SCE, then a pure strategy equilibrium in which the path is constrained from south-to-north does exist.

We examined these conditions under a range of values for the flow capacity of path 15 . We found that for the existing patb capacity of around $3500 \mathrm{MW}$, the passive/aggressive equilibrium that congests path 15 is indeed a pure strategy equilibrium. This held for capacities up to about $4100 \mathrm{MW}$. For path capacities over $4100 \mathrm{MW}$ but less than $4630 \mathrm{MW}$, we found that PG\&E would prefer to respond to SCE's aggressive output by expanding its own output, thereby leaving path 15 unconstrained. For path capacities in this range, however, PG\&E still prefers the outcome of a passive strategy to the unconstrained Cournot outcome. We conclude that only mixed strategy equilibria exist for path capacities in this range, the situation described as the nonoverlap case in the previous section. ${ }^{43}$ For path capacities of $4630 \mathrm{MW}$ and above, PG\&E prefers the unconstrained Cournot equilibrium to ones that arise from playing the passive strategy.

\footnotetext{
${ }^{43}$ We did not attempt to find the mixed strategy equilibria in these cases.
} 
This capacity, $4630 \mathrm{MW}$, is the threshold line size that yields the unconstrained Cournot equilibrium during this hour.

Table 3 contrasts the market outcomes for path capacities of $4630 \mathrm{MW}$ with those for the actual path capacity of $3500 \mathrm{MW}$. Total output in the state (including imports from the desert southwest and Mexico) increases from 31,132 MW under the passive/aggressive equilibrium to 34,749 under the unconstrained Cournot equilibrium. Thus, the ratio of additional output to additional line capacity for this marginal change is about 3.2:1.

Market clearing prices drop by $59 \%$ in the south and by $93 \%$ in the north when transmission capacity is increased enough to achieve the unconstrained Cournot outcome. ${ }^{44}$

\begin{tabular}{|c|c|c|}
\hline Path 15 Capacity & $3500 \mathrm{MW}$ & $4630 \mathrm{MW}$ \\
\hline \hline PG\&E output & $798 \mathrm{MW}$ & $2635 \mathrm{MW}$ \\
\hline California output & $31,132 \mathrm{MW}$ & $34,749 \mathrm{MW}$ \\
\hline N. California Price $(\phi / k W h)$ & 95.13 & 6.31 \\
\hline S. California Price $(\phi / k W h)$ & 15.53 & 6.31 \\
\hline
\end{tabular}

Table 3: The impact of increased transmission capacity

It is also interesting to examine the market outcomes under the assumption that the market in southern California is perfectly competitive. If this were the case, even if path 15 had a capacity of $4630 \mathrm{MW}, \mathrm{PG} \& \mathrm{E}$ would reduce output and congest the path since the unconstrained Cournot outcome is no longer an alternative. If path 15 were congested, the northern California market would have a price of $23.4 \phi / k W h$ as opposed to the Cournot price of $6.31 \phi / k W h$. Thus, for path 15 capacities in

\footnotetext{
${ }^{44}$ Of course, regulatory pressure might very well prevent persistent prices as high as $95 \% / k W h$, but this still illustrates the market operation in the absence of regulation.
} 
this range,${ }^{45}$ consumers in northern California may be better off if the southern California market is less competitive.

These results indicate that strategic congestion of transmission lines may play an important role in the forthcoming deregulated electricity markets. These effects would not be captured by the most widely used methods for estimating the scope of geographic markets in this industry that rely upon historical flow data or the simulation of a perfectly competitive regional market. Such methods could fail to recognize some of the most tangible benefits that might result from expansion of transmission capacity.

\section{Conclusions}

Transmission constraints will be at the heart of market power issues in a restructured electricity market. In the absence of transmission constraints in the western U.S., it is unlikely that any firm would have sufficient market power to significantly elevate prices. Transmission congestion, however, is likely to occur at some times. This paper has made a preliminary exploration into the market power issues raised by the central role of transmission and the resulting possible benefits to increasing transmission capacity. We have shown that the social value of transmission capacity may not be closely related to the actual flow that occurs on the line. We also have demonstrated how to analyze the impact of transmission capacity on competition. Our results indicate that expanding transmission capacity between markets that suffer from market power problems may have very high payoffs in terms of reduced prices, increased consumption, and lower deadweight loss.

\footnotetext{
${ }^{45}$ For a path 15 capacity of less than $4000 \mathrm{MW}$, additional competition in the south would have no effect on prices in the north since PG\&E prefers to congest path 15 anyway.
} 
Our analysis, however, has considered only one-shot Nash equilibria with a single dominant firm in each regional market. In reality, the firms that compete in electricity markets will do so repeatedly and, thus, may be able to reduce rivalry through the threat of retaliation. To the extent that firms can reach more cooperative outcomes through such supergame strategies, the competitive effects of transmission lines, as well as most other remedies for the exercise of market power, are likely to be dampened.

Entry of new producers could also mitigate the effects that we identify here. If entry in the two markets is easy, then sufficient entry in each market could produce as great or greater competitive effects as increasing transmission capacity. It is important to note that entry would have to occur in both markets for it to replicate the competitive effect of a transmission line that we have demonstrated here. If, however, there are sunk costs of entry or fixed costs of operation, then the transmission capacity could be a less expensive route to achieving the benefits of increased competition. 


\section{References}

Borenstein, S. and Bushnell, J.B. (1997). "An Empirical Analysis of the Potential for Market Power in California's Electricity Market." POWER Working paper PWP-044. University of California Energy Institute.

Borenstein, S., Bushnell, J.B., and S. Stoft (1996). "The Competitive Effects of Transmission Capacity in a Deregulated Electricity Market." POWER Working paper PWP-040. University of California Energy Institute.

California Energy Commission (1995). 1994 Electricity Report. Data appendices

Cardell, J.B., C.C. Hitt, and W.W. Hogan (1996). "Market Power and Strategic Interaction in Electricity Networks." Working Paper, Harvard Electricity Policy Group. September.

Davidson, C., and R. Deneckere (1986). "Long-run Competition in Capacity, Short-run Competition in Price, and the Cournot Model." Rand Journal of Economics. vol. 17, no. 3, pp. 404-415.

Fudenberg, D. and D.K. Levine (forthcoming). Theory of Learning in Games, (Cambridge, MA.: MIT Press).

Fudenberg, D. and Tirole, J. (1991). Game Theory; (Cambridge, MA.: MIT Press).

Green, R.J., and D.M. Newbery (1992). "Competition in the British Electricity Spot Market." Journal of Political Economy. vol. 100, no. 5, pp. 929-953.

Klemperer, P.D. and M.A. Meyer (1989). "Supply Function Equilibria in Oligopoly under Uncertainty." Econometrica, vol. 57 , no. 6 , pp. $1243-1277$.

Kreps, D.M. and J.A. Scheinkman (1983). "Quantity Precommitment and Bertrand Competition Yield Cournot Outcomes. "RAND Journal of Economics, vol. 14, no. 2, pp. 326-337.

Oren, S.S. (1997). "Economic Inefficiency of Passive Transmission Rights in Congested Electricity Systems with Competitive Generation." The Energy Journal. vol. 18, no. 1, pp. 63-83. 
Pace, J., (1996). "Market Power Analysis of Pacific Gas and Electric Company In Support of Joint Application", Federal Energy Regulatory Commission, Docket No. ER96-1663-000.

Bohn, R.E., M.C. Caramanis, and F.C. Schweppe (1984). "Optimal Pricing in Electricity Networks Over Space and Time," RAND Journal of Economics. vol 15, no. 3, pp. 360-376.

Schweppe, F., M. Caramanis, R. Tabors and R. Bohn (1988). Spot Pricing of Electricity, Kluwer Academic Publishers.

Shapley, L. (1964). "Some Topics in Two-Person Games" in Advances in Game Thoery, Drescher, Shapley, and Tucker, eds., (Princeton: Princeton University Press).

von der Fehr, N. and D. Harbord (1993). "Spot Market Competition in the UK Electricity Market," Economic Journal, vol 103, pp. 531-546.

Western Systems Coordinating Council (WSCC, 1996). Path Rating Catalog. Revised, February.

Wolak, F.A. and R.H. Patrick (1996). "The Impact of Market Rules and Market Structure on the Price Determination Process in the England and Wales Electricity Market," mimeo, Stanford University.

Wolfram, C.D. (1996), "Measuring Duopoly Power in the British Electricity Spot Market," mimeo, Harvard University. 


\section{Appendix A}

Proof of Result 4: If we assume result 4 is not true, then one of three cases must hold. There will either be an asymmetric equilibrium where the line is congested, an asymmetric equilibrium where the line is not congested, or a symmetric equilibrium where both players play some quantity less than the Cournot quantity (and the line is uncongested). We can easily rule out the last two possibilities by observing that, since the line is unconstrained, each player would prefer to change its production to its unconstrained Cournot best response. ${ }^{46}$ Thus, the only pure strategy equilibrium with an uncongested line is the unconstrained Cournot duopoly equilibrium. We therefore restrict our attention to asymmetric equilibria where the line is congested.

First, we note that there cannot be an asymmetric, congestedline equilibrium where neither player is playing the passive strategy, since the passive strategy is by definition the best response of the producer in the market that the congested line is flowing in to. We now show that there cannot exist an asymmetric pure strategy equilibrium in which one player utilizes the passive strategy, $Q_{m}^{-}$.

We know from the arguments of section 3 and above that if an equilibrium exists in which the passive firm is producing $Q_{m}^{-}$ and the line in to its market is congested, then the aggressive firm must be producing at least $Q_{m}^{-}+2 k$, the minimum quantity that would congest the line. We now show that the aggressive firm would never want to produce more than $Q_{m}^{-}+2 k$ in response to $Q_{m}^{-}$, so it could only be producing exactly $Q_{m}^{-}+2 k$ in this potential equilibrium.

To see that this is the case, recall that $Q_{m}^{-}>Q_{m}-k$, which implies that $Q_{m}^{-}+k>Q_{m}$. When the aggressive firm produces $Q_{m}^{-}+2 k$ and $k$ is shipped to the other market, this leaves the firm producing $Q_{m}^{-}+k$ for sale in its own market, which we have just shown would be greater than the profit-maximizing quantity for its own market in isolation. Considering that, under nodal pricing, additional output that is consumed in its own market

\footnotetext{
${ }^{46}$ As noted in footnote 5 , we are assuming that, absent transmission constraints, a firm's profit function is always concave in its output.
} 
also drives down the price that the aggressive firm receives for power that is shipped to the other market, it is clear that it would not want to further expand output beyond the quantity $Q_{m}^{-}+2 k$, which just congests the line.

So, the only possible candidate for an asymmetric, purestrategy equilibrium is one firm producing $Q_{m}^{-}$and the other producing $Q_{m}^{-}+2 k$. For this to be an equilibrium, it must be the case that the passive strategy, $Q_{m}^{-}$, is the best response to the aggressive firm's $Q_{m}^{-}+2 k$. But production of $Q_{m}^{-}+2 k$ in response to $Q_{m}^{-}$just barely congests the line, i.e., if the passive firm increased its output by $\epsilon$, it would decongest the line. This means that the profits that the passive firm earns in this outcome lie on its unconstrained profit function, i.e., the profit function it would face if each firm produced these quantities, but there were no line constraint. This firm's unconstrained profit function is, by assumption, strictly concave, and its profit maximum is its Cournot best response, which is greater than the passive strategy output. Thus, the passive strategy cannot be a best response to $Q_{m}^{-}+2 k$. Therefore, there cannot be an asymmetric pure strategy equilibrium involving the passive strategy.

Proof of Result 5: The existence of the two cases we prove by example in the text. Here, we prove that the necessary and sufficient condition for the existence of two pure-strategy equilibria for some line capacities (the overlap case) is that the unconstrained Cournot equilibrium output of the producer in the lowprice market is less than that firm's best response when the firm in the high-price market plays the passive strategy, $Q_{c}^{s}<Q_{m}^{s+}$.

Consider the threshold line size $k *$ which would support the unconstrained Cournot duopoly equilibrium. By definition, $k *$ is the line size at which (at least) one firm is indifferent between the Cournot equilibrium and playing the passive strategy. Consider the case in which firm $n$ is indifferent at line size $k *$. Assume that it chooses to play the passive strategy and firm $s$ responds by increasing its output (from $Q_{c}^{s}$ ). An increase in firm $s$ 's output has no effect on firm $n$ 's profits from playing the passive strategy, since the line was congested anyway. But it lowers the profitability of firm $n$ responding with an unconstrained Cournot best response, because the profit of one firm is decreasing in the output of the other firm in a Cournot game. 
Since firm $n$ was previously just indifferent between the passive strategy and its unconstrained Cournot best response, it would now strictly prefer the passive strategy. Thus, if firm $s$ 's response to firm $n$ playing the passive strategy is to increase its own output, this reinforces firm $n$ 's preference for the passive strategy. Since both firms are then playing their best responses to the other, this passive/aggressive outcome is a Nash equilibrium.

Next consider the case in which the firm that is indifferent at line size $k *$, firm $n$, chooses to play the passive strategy and firm $s$ responds by decreasing its output. A large enough decrease in the firm $s$ 's output would decongest the line. This would yield a decongested line with each firm producing less than its Cournot best response, which cannot be an equilibrium, by the arguments in the text and the proof of result 4. A small decrease in firm $s$ 's output would not decongest the line. This would have no effect on the profits of playing the passive strategy, since the line remains congested. But it would increase firm n's profitability of responding to firm $s$ with an unconstrained Cournot best response. Since firm $n$ was previously just indifferent between the passive strategy and its unconstrained Cournot best response, it would now strictly prefer the Cournot best response. Thus, the passive/aggressive outcome would not be an equilibrium. 